\title{
Toys for Boys? Women's Marginalization and Participation As Digital Gamers
}

\author{
by Garry Crawford and Victoria Gosling \\ Sheffield Hallam University and Nottingham Trent University
}

\author{
Sociological Research Online, Volume 10, Issue 1, \\ < http://uww. socresonline.org.uk/10/1/crawford.html> \\ doi:10.5153/sro. 1024
}

Received: 7 Sep 2004 Accepted: 30 Nov 2004 Published: 31 Mar 2005

\begin{abstract}
This paper develops out of ongoing research into the location and use of digital gaming in practices of everyday life. Specifically this paper draws on a questionnaire based survey of just under four hundred undergraduate students and twenty-three follow up interviews. This paper suggests that the women in this research play digital games significantly less than their male counterparts, and suggests that this is largely due to digital games continuing to be viewed, both culturally and by the gaming industry, as belonging to men. However, this paper suggests that for some women video and computer gaming can be an important social activity, and for others mobile telephone based gaming can offer a less restricted and more accessible leisure activity.
\end{abstract}

\section{Keywords: Gender, Digital Gaming}

\section{Introduction}

1.1 This paper develops out of ongoing research into the use and location of digital gaming in practices of everyday life and social interactions. It draws on data gathered from a questionnaire administered to around four hundred undergraduate students in Sheffield, and twenty-three follow up face-to-face interviews. The original purpose of this research was to offer some insight into contemporary gaming patterns, and in particular, to investigate the relationship between digital gaming and levels of sport participation and interests. Findings from this research, and specifically those pertaining to patterns of sport participation and gaming, are considered further elsewhere (Crawford 2005). However, in this paper we wish to focus more specifically on gendered patterns in digital gaming observed in this data and offer some possible explanations for these.

1.2 To date there is still relatively little empirical research conducted on the practices and patterns of adult digital gamers, and in particular, little research on the relationship between the use of information and communication technologies and gender (Green 2001). Though it was not the initial aim of the survey and interviews to seek out and identify gender differences, the subsequent analysis of this data highlighted some contrasting patterns and interests in digital gaming of male and female respondents and interviewees. In particular, this paper argues that the women in this sample appeared less likely to play digital games, and those who did, played these less frequently than their male peers.

1.3 These findings support the assertion that women continue to constitute an overall minority of gamers in the UK (Krotoski 2004). However, data gathered for this paper does not necessarily contradict the findings of studies conducted on school children (such as Funk 1993, Kafai 1996, Roe and Muijus 1998, Littleton et al. 1998,Colwell and Payne 2000), which suggest that within this age and social group gaming for girls is increasing.

1.4 The argument offered in this paper is that though more girls may be playing games within a family home environment, leisure technologies, such as computers and games consoles, continue to be both physically and symbolically controlled by men (McNamee 1998). Though many women do play digital games, this is still frequently something that they are granted or restricted access to by male family members. Hence, this remains symbolically and culturally not theirs, and hence is something they are less likely (than their male peers) to carry on outside of the family home, such as at university.

1.5 However, focusing solely on women's marginalization within digital gaming culture, overlooks those who actively participate within this and the meaning and social importance these activities may hold in their 
everyday lives. Too often issues of gender constitute an afterthought in many studies of popular culture. Attention continues to be focused primarily upon the cultural activities of men, while many studies of women only highlight their marginalization and lack of participation. For instance, this has been particularly evident in studies of sport fan culture (seeCrawford and Gosling 2004). However, doing so ensures that consideration of popular culture remains firmly focused upon men's participation, and we learn little about the activities and interests of women who do participate in male dominated cultures, such as digital gaming. Hence, this paper provides a consideration, not only of women's marginalization from gaming culture, but also the participation patterns and interests of those women within the sample who did play digital games.

1.6 For, it is evident from this research that some women (though in a minority compared with their male peers) do play digital games. For some women digital gaming can be a sociable activity, which may lead to conversations and social interactions away from the gaming screen. While, for other women, mobile telephones appear to offer a source of leisure and entertainment (though largely individual), which is less restricted than other gaming technologies.

1.7 This paper does not aim to provide broad generalisations for all female gamers, but rather provides a consideration of the patterns of play, experiences and attitudes of a sample of university students, and highlights the importance of gender relations in constructing and shaping the complex position that women occupy as digital gamers.

\section{Considering Digital Gaming and Gender}

2.1 Digital gaming is over forty years old, however it was not until the late 1970s and 1980s that digital gaming began to develop as a major leisure industry, with the rapid rise in popularity of arcade based games such as Space Invaders and the introduction of home based video games consoles and home computing, such as the release of Nintendo's Famicom and the Commodore 64 both in 1983 (Digiplay n.d.). Today, digital gaming is a major global leisure industry. More digital games are sold in the US and UK than books (Bryce and Rutter 2001) and leisure software sales in the UK outstrip those of both cinema box office takings and VHS/DVD rentals (ELSPA 2003). The largest digital games market is still undoubtedly in the US, where a recent poll by the Entertainment Software Association (ESA) suggested that 41 percent of all Americans, and 63 percent of parents, planned on purchasing at least one digital game in the following year (ESA 2004). In the US alone, digital games software sales in 2003 were worth in excess of $\$ 7$ billion, and this figure continues to rise each year (ESA 2004), and following the US and Japan, Britain constitutes the world's third largest games market (ELSPA 2003).

2.2 Digital gaming has often been seen as an (almost) exclusively male activity, with research in the 1980s and 1990s consistently suggesting that digital gaming was dominated by male participation (seeColwell, Grady and Rhaiti 1995,Buchanan and Funk 1996). In particular, Bryce and Rutter (2003b) offer some possible explanations as to why women have been traditionally marginalised within digital gaming. First, women continue to be much more restricted in their leisure choices and opportunities than men (Deem 1982, 1986, Shaw 1994,Wearing 1998). This is due to numerous social factors, such as restrictions placed upon women's presence in many 'public' places, economic constraints, domestic and caring responsibilities, the limited leisure time of many women, and social expectations of women's location and roles within society (also see Krotoski 2004). Second, women often lack equal access to technology. For instance, it is evident that boys tend to dominate computer technology at school, and hence, these frequently prove 'unpopular' with many girls (Green 2001). Third, it is argued that the themes and goals of digital games often do not reflect the interests of many women. Kinder (1991) suggests that digital games are designed primarily (if not solely) for male audiences, and most commonly feature 'male' themes, such as violent and sport related contents, and tend to lack female protagonists. Moreover, when female characters are featured within games, these are usually portrayed in sexualised or passive roles (Greenfield 1996, Kafai 1996, Dietz 1998,Bryce and Rutter 2002).

2.3 However, it has been suggested by some that the number of female digital gamers has began to increase in recent years, as women begin to make inroads into this (once) male-dominated domain (Cassell and Jenkins 2000). As both a consequence and contributing factor of these changes, Bryce and Rutter (2003a) suggest, that the themes and contents of many digital games have become less gendered, with more featuring female characters and less 'male' dominated themes and narratives. In particular, there are a growing number of studies that suggest that women now constitute a sizable proportion of game players and purchasers, such as Colwell and Payne (2000) who suggest in their survey of 204 school children that 87.6 percent of girls compared with 96.7 percent of boys played digital games. However, the majority of empirical studies on gender and gaming practices (such asFunk 1993, Kafai 1996, Roe and Muijus 1998, Littleton et al. 1998, Colwell and Payne 2000) are largely (if not solely) based on surveys of school children, and a recent survey conducted for the Entertainment and Leisure Software Publishers Association (EPSPA) suggests that female gamers constituted only around 27 percent of all current UK 


\section{The Research}

3.1 The data drawn on in this paper was gathered from a questionnaire-based survey and follow-up interviews. The questionnaire was distributed to 392 undergraduate students at Sheffield's two universities studying on Sociology, Social Work or Cultural Studies degrees at the end of 2003 and beginning of 2004. This questionnaire consisted of thirty short, mainly closed-ended, questions. This was then followed up via (to date) twenty-three (eleven male and twelve female) face-to-face interviews with students, who were selected simply on the basis of their willingness and availability to participate in a follow up interview.

3.2 Relying solely on a convenience sample of undergraduate social science students does provide a skewed sample in respect of age, ethnicity, gender and social class. For instance, though the age of respondents in the questionnaire sample group does range from 18 to 55, 91 percent of these were between the ages of 18 and 21 . It is also notable that nearly 99 percent of respondents indicated their ethnicity as 'white'. Hence, it is questionable whether the results gathered here are necessarily representative of a general adult population. However, to date the vast majority of empirical research on patterns of gaming rely largely (if not solely) on sample groups of children, who still live in their family homes. Hence, sampling a group of university students provides the opportunity to consider adults, in a situation where the majority of these will have moved away from their family home for the first time, and to assess, if gaming patterns previously noted in children carry on into adult life.

3.3 Furthermore, the skewed demographics of this sample proved beneficial in obtaining an almost equal gender balance in respondents who indicated that they had recently played a digital game. Due to social science degrees generally attracting a high proportion of female students, 63 percent (of the total 392) questionnaire respondents were female. However, significantly fewer women (only 50 percent of women, compared with 93 percent of men) indicated that they had played a digital game 'in the last three months'. Hence, this provides a sub-sample of 133 men (from an overall sample of 143) and 124 women (from an overall sample of 249) who had recently played digital games.

3.4 Not all respondents were required to answer every question on the questionnaire. For instance, only those who indicated that they had played a 'sport related' digital game 'in the last three months' were required to answer questions relating to these. Hence, the number of respondents to each particular question can vary significantly; therefore the number of respondents each percentage is drawn from is clearly indicated throughout the paper.

\section{Women and Digital Gaming}

4.1 The research data gathered for this paper suggests that the women were considerably less likely to have played a digital game in the last three months than their male peers. As already highlighted, digital games had recently been played by the vast majority of male but only around half of the female respondents to the questionnaire. It is also evident that of the women who did play digital games, most tended to play these a lot less frequently than their male counterparts. As Table 1 indicates, of those who indicated that they had played a digital game, 66 percent of men (compared with only 23 percent of women) suggested that they played these at least 'two or three times a week', while 34 percent of women (compared with 8 percent) indicated that they played digital games only 'once a month' or less.

Table 1: Percentages of how frequently respondents play digital games (number) $\left(N=254, x^{2>}=57.284, p<.001\right)$.

\begin{tabular}{llll}
\hline Frequency & Overall & Male & Female \\
Most days & $22.0(56)$ & $34.6(46)$ & $8.3(10)$ \\
2 or 3 times a week & $23.6(60)$ & $31.6(42)$ & $14.9(18)$ \\
Once a week & $16.1(41)$ & $14.3(19)$ & $18.2(22)$ \\
2 or 3 times a month & $18.1(46)$ & $12.0(16)$ & $24.8(30)$ \\
Once a month & $9.4(24)$ & $5.3(7)$ & $14.0(17)$ \\
Less than once a month & $10.6(27)$ & $2.3(3)$ & $19.8(24)$ \\
\hline
\end{tabular}

4.2 These figures support the recent assertions of Krotoski (2004), which suggest that women constitute less than a third of 'active gamers' in the UK, but contrasts with many studies conducted on school children that tend to show higher levels of female participation. 
4.3 It could be argued that these variations can be explained by generational differences. The argument could be formulated that studies on school children focus upon a younger generation of gamers [than this study and the data (Krotoski 2004) draws on], who may be more likely to continue their interest in digital gaming as they grow older. However, most of these studies on school children we cite here were conducted in the 1990s (often in the early 1990s), meaning most of these are now over ten years old. Hence, it is unlikely that these variations could be explained by generational differences. It is more likely that these may be explained by age and social differences between the different sample groups. Though little information is given on the data set Krotoski draws on, it is evident that the data she uses employs a wider age range sample than just school children. While data we use in this paper is drawn from a sample group, who were all over the age of 18 , and the vast majority were living away from their family homes. Hence, the picture that can be derived from this and previous studies on women's digital gaming participation rates, suggests that while young girls may be increasingly likely to play digital games while living in their family homes, women appear less likely (than their male peers) to continue gaming away from here and into adult life.

4.4 It is evident that the vast majority of digital gaming takes place in a domestic setting (Kerr 2003). Moreover, Bryce and Rutter (2003a, 2003b) suggest that this may be even more so for female gamers who often find themselves excluded from more 'public' gaming environments, such as arcades and gaming competitions and conventions. As they write:

As domestic spaces have been traditionally conceived as the site of female leisure, it may be argued that the constraints on female participation and access to computer gaming in these spaces might be less rigid than in public gaming spaces, and that the domestic space provides a less gendered gaming environment in which female access and participation is more easily negotiated (Bryce and Rutter 2003b: 9).

4.5 In particular, Kerr (2003: 4) suggests that male social networks (and particularly male family members) appear crucial in 'enrolling and socialising female players', and of the four female interviewees who had male siblings, all suggested that digital games were something they would frequently play and discuss with their brothers. As 'Julie' (female, aged 20) indicated:

...computer games is something l'd talk about with my brother before I left [for university]. I still do sometimes when I go back, 'cos like, he'll wanna talk...[to] me about the latest game he's got, or like what levels he's got to, and we'll talk about stuff like that, but not at uni'...[...].. I, we still play games together as well, like when I'm back, but obviously not as much as we used to.

4.6 Kerr (2003) suggests that many men and boys are quite willing to initiate women (such as their sisters) into gaming culture. However, digital gaming still appears primarily a male domain into which women frequently have to be granted access by men. For instance, Green (2001) suggests that within many households leisure technologies (such as computer and games consoles) continue to be primarily located within 'male' spaces (such as male sibling's bedrooms, and studies). Moreover, McNamee (1998) suggests that even when games machines are located in shared 'family' spaces, conflict often arises as these continue to be seen as symbolically belonging to male household members. Green (2001: 181-2), citing Silverstone et al. (1992), suggests that households will often be structured around a 'moral economy' that is expressed through symbolic and material boundaries, which dictates expected gender roles,

responsibilities and spheres, and this frequently locates leisure technologies as male possessions. Hence, digital gaming continues to be viewed by many (both men and women) as culturally not 'belonging' to women, but rather something they are (sometimes) allowed access to in their family home.

4.7 Kerr (2003: 14) argues that continued participation in digital gaming for many women relies heavily on the presence of a local and physically accessible community of game players. Hence, this research suggests that away from their family homes (such as at university) women appear less likely to continue digital gaming. In particular, this was evident in the follow up interviews. For instance, two female respondents indicated that they used to, but no longer, played digital games. In both cases, these interviewees indicated that they jointly owned game consoles with male siblings, but in one case, this remained with the brother when she went to university and in the second, the two consoles they jointly owned were both taken away to university by her elder brother:

We, me and my brother, had two Playstations... Like, a PSone and a Playstation 2, but me brother took both of them to uni' when he went, so I don't play any games anymore...I would like, if he hadn't taken 'em both, but he said he wanted one in his bedroom at uni', and like the other in their living room to play on. So he's got 'em both...[laughs] ('Julie', female, aged 20). 
4.8 It is also evident that gender roles are played out and performed in different ways, in different social settings, and at different points in a person's lifecourse. For instance, this has been noted in relation to the educational and extra curricula activities girls 'select' (or more commonly, are 'socialized' or 'guided' into) during their schooling and beyond (Pilcher 1999). At university, where women are most likely to be living in all-female student households, this may not only reduce the likelihood that they will encounter others who play digital games, but may also mean that their gender identities are constructed in particular ways that may exclude participating in activities that are deemed 'masculine' (such as digital gaming). However, this is an area that requires further research.

4.9 However, it would also be wrong to assume that all women necessarily want to play digital games, and are restricted from doing so. Though Haddon (1992) suggested that there was no discernable difference between boys and girls' desire to play digital games, women are not homogenous and will have different experiences, interests and desires, and within this research two female interviewees indicated that they had no interest in digital games at all. Such as the comments made by 'Libby' (female, aged 19) who, when she was asked if she had ever played a digital game, responded:

No...Maybe once or twice in my whole life...I don't like the violent ones because I don't like the violence. I just have no interest in them whatsoever and think that's half the reasons why kids today are so anti-social.

4.10 'Libby' did have people around her who played digital games, as both her brother and university housemates (who were all women) played digital games, and these had in the past encouraged her to play, but she indicated that these were 'simply not my thing'. However, when asked why these were 'not her thing', 'Libby' indicated that her perception of the dominant themes within these (and most notably she identified violent and sport related themes), were not of interest to her 'as a woman'. Hence, it is the 'masculine' themes of many (if not most) digital games, which 'Libby' identifies as not appealing to her.

4.11 Though it is suggested that the content and themes of digital gaming may be changing, the majority of these still appear primarily produced and marketed towards a male audience. In particular, all of the interviewees (both male and female) indicated that they felt that the majority of digital games were not designed for, or aimed at, women (also seeBryce and Rutter 2003a). In particular, Kerr (2003) suggests that games designed specifically for women may prove unpopular for most men, who continue to constitute game designers and publishers' key target audience.

4.12 For instance, in this survey sport related games proved less popular with most of the women, than their male counterparts. When respondents were asked to indicate their favourite genre of digital game, sport related games proved by far the most popular type of game for male respondents, however, these were only the joint-third most popular type of game for women (see Table 2).

Table 2: Percentages of respondents' favourite types of digital game (number) $\left(N=163, x^{2>}=50.543, p<.001\right)$.

\begin{tabular}{llll}
\hline Type of Game & Overall & Male & Female \\
Sport & $38.0(62)$ & $88.7(52.4)$ & $12.1(7)$ \\
Action (e.g. shoot 'em ups) & $14.7(24)$ & $17.1(18)$ & $10.3(6)$ \\
Strategy/war gaming/'god' simulations & $11.0(18)$ & $11.4(12)$ & $10.3(6)$ \\
Platform & $9.2(15)$ & $2.9(3)$ & $20.7(12)$ \\
Adventure/RPGs & $8.6(14)$ & $7.6(8)$ & $10.3(6)$ \\
Driving/racing & $6.7(11)$ & $1.9(2)$ & $15.5(9)$ \\
Fighting (e.g. beat 'em ups) & $6.7(11)$ & $5.7(6)$ & $8.6(5)$ \\
Other & $4.9(8)$ & $1.0(1)$ & $12.1(7)$ \\
\hline
\end{tabular}

4.13 These figures are likely to be explained by the tendency for sport related games to be based most commonly on male participation sports, such as soccer, American football, ice hockey and basketball. Generally, these types of games proved popular with male respondents to the questionnaire, but far less so for women. Of the female respondents who indicated that they had recently played sport related digital games $(N=47)$, multi-sport games (e.g. track and field and winter sports), and less gender specific games, such as golf and skateboarding, proved more popular than with male respondents (Crawford 2005).

4.14 T.L. Taylor (2003) suggests that many women want, at least the option, to be able to play female 
characters (or 'avatars') in digital games, and the follow up interviews did indicate a reluctance by some women to play games that featured exclusively male protagonists - such as many sport related games. Such as the comments made by 'Laura' (female, aged 20):

I play like surfing and skateboarding games, 'cos they interest me, and you can be women in it...but stuff like mens' football don't interest me, why would I wanna pretend to be a bloke? Maybe if they made women's football games that would be different, but they won't will they, 'cos no blokes'd play them...

4.15 There is some debate as to whether digital games should, or should not, be specifically tailored to meet what are seen as the interests and needs of the female games market. In previous years, there has been a (slight) increase in software titles and companies targeted towards a female market, however, these still tend to be extremely rare and have frequently been aimed at stereotypical ideas of femininity and feminine interests, such as (the hugely successful) Barbie Fashion Designer (Jenkins 2000).

4.16 However, as stated earlier, focusing merely on the marginalization of women as gamers overlooks those who do play these games and those who actively participate in this culture. In particular, Bryce and Rutter (2003a) argue that not all female gamers want games specifically designed for women, particularly those based upon (often sexist) gender stereotypes. Bryce and Rutter point towards the literature on 'oppositional reading', such as that articulated by authors like Fiske (1989a, 1989b) and Jenkins (1992), which suggest that readers of cultural texts (be these book, television shows, or digital games) can often reinterpret and 'play' with these texts. They point towards Yates and Littleton's (2001) consideration of female gamers, who they suggest often 'reinterpret' games such as Tomb Raider. In particular, Yates and Littleton (2001: 113) argue that though 'Tomb Raider sets up a classic male...position for the player...in which the female (in this case Lara Croft) is passively watched', it also offers gamers (and in particular female gamers) the opportunity to take the position of an active female character (even if this is an exaggerated and sexualised female figure conceptualised and modelled from a male perspective). Cassell and Jenkins (2000) also highlight the popularity of so-called 'male' genres of digital gaming (such as firstperson-shooters, like Quake and Doom) with certain female (or 'grrl') gamers. This is supported in this research by two female interviewees who suggested that they enjoyed playing sport related digital games; which would have been primarily designed and marketed towards a male audience. For instance, 'Cathy', (female, aged 20) indicated that playing FIFA (a soccer based game) was a regular social event in her student household, and moreover, conversations about this would often continue on away from the game and household. As she stated:

We [her student household] got FIFA on the PSOne [Playstation] and we talk about that all the time, like who beat who, and how we're gonna get 'em back so bad next time...it's such a laugh really.

4.17 Taylor (2003) suggests that many women enjoy the sociability of gaming, and as with many male players, women will often continue conversations about games away from the sight of the game screen. This quote from 'Cathy' also supports Taylor's assertion that some women can be quite competitive in their gaming.

4.18 However, Cassell and Jenkins (2000) suggest that it is important that the rising number of women playing games primarily written and marketed towards men, should not be seen as reason to overlook the needs and interests of women. For, as they suggest, a great deal of feminist scholarship in recent years has focused around 'reclaiming and revaluing women's traditional cultural interests and competencies' (Cassell and Jenkins 2000: 21).

4.19 However, Cassell and Jenkins (2000: 15) warn that creating 'female' specific games may ghettoise these gamers and their games, further marginalizing the location of women in digital gaming culture. Case (2004) suggests that what most female gamers want, is more gender neutral games, and not those that necessarily reflect either (often stereotyped) 'male' or 'female' interests. This was highlighted most notably by 'Laura' (female, aged 20):

They [digital games] are all bloke stuff, like shooting and football. My brother's right into all that shootin' up zombies stuff, but it just ain't...it don't interest me...nor any of my friends. I'm not saying I want pink ribbons and stuff [laughs], but l'd be more interested in like if maybe they made different games...not necessarily games just for girls...but they're all the same...

4.20 The development of new gaming input devices based upon playing musical instruments or dancing, such as drums, maracas and dance mats have proved popular with both sexes and a range of age groups, but particularly so for young women (Krotoski 2004). Though games based around these input devices can involve competitive elements, Krotoski (2004) suggests they have introduced more of a 'party' element into 
gaming. This is highlighted quite noticeably by one interviewee, 'Lisa' (female, aged 21):

...like when we came to uni', one of my friends bought one of those dance mats out for her Playstation and like there's six girls in our house, we just thought it was so funny dancing around in it. Yes, so like pretty much the only sort of game thing I do because l've got no coordination at all when I try do it like football games, I'm like 'oops my players running backwards to the other goal' ....but no it's just the dance mat thing really.

4.21 Once again, this reinforces the 'social' appeal gaming can have for some women (Taylor 2003). However, women who play 'male' themed games and those who participate in gaming within group settings, continue to be a small minority of gamers. Moreover, when questionnaire respondents were asked if they played digital games on a list of different gaming platforms, the only format that proved more popular with women than men was mobile telephones, which tend to feature (almost exclusively) simple single player games.

4.22 Of the 95 individuals who indicated that they would 'usually' play games on their mobile telephones (see Table 3), 62 of these (65 percent) were female. In particular, nearly a third of these (19 women) indicated that they only played games on their mobile phones, while in comparison, all of the 33 men who suggested that they played games on their mobile telephones also played games on either PC/Macs and/or games consoles.

Table 3: Percentage of respondents who 'usually' played digital games on each particular games platform (number) $(N=257)$.

$\begin{array}{ll}\text { Platform } & \text { Overall } \\ \text { Console } & 75.5(194) \\ \text { PC/Mac } & 54.1(141) \\ \text { Mobile } & 37.0(95) \\ \text { Handheld } & 9.7(25) \\ \text { PDA } & 2.7(7) \\ \text { Other } & 0.8(2)\end{array}$

4.23 Though this is only a relatively small-scale sample, these figures appear to support the assertion that mobile telephones provide a popular gaming platform for many women (see Krotoski 2004). A possible explanation for this is that mobile telephones may be imbued with a lot less gender significance than computers or game consoles, as telephones are often located within more shared 'family' spaces, and for many women, have been an important connection to the 'public' world outside of their homes (Frissen 1995). Similarly, mobile telephones do not need to be located within specific (gendered) places within the home, but are rather items carried about the person, and access to these as both a form of communication and source of entertainment and leisure (both via gaming and other services such as text messaging and WAP) is likely to be less restricted for women than many other information and communication technologies.

4.24 Another important aspect of mobile telephone gaming is that the games played on these tend to be simple and quick 'mini games'. Krotoski (2004) suggests that women's leisure time continues to be restricted by numerous social factors, such as continued domestic responsibilities, and hence games that require less time commitments such as puzzle, platform or racing games proved particularly popular with many women. It is also notable that most 'mini' games tend to be fairly gender neutral, as most are puzzle based and rarely feature gender specific characters or themes.

4.25 These assertions are also borne out by this research. As table 2 indicates (see earlier) the most popular genre of games for female respondents were 'platform games' (21 percent) and 'driving/racing' games (15 percent). Also of the 8 respondents who indicated that their favourite game was 'other', 7 of these were women. Moreover, when asked to specify what type of 'other' game they played, all of these respondents named various 'mini' games, such as those played on mobile phones. Such as 'Leanne' (female, aged 21) who stated: 'I just play Solitaire and FreeCell on PC all the time, but that's it...[and] Snake and Pairs [on her mobile phone]. But mostly Snake'.

4.26 These findings are further supported by data, which suggests that generally women appeared less likely to play digital games with other people. When respondents to the questionnaire were asked how frequently they played games with other people 'in-person' on a scale of 'every time', 'most of the time', 
'occasionally', 'infrequently' or 'never', 41 percent of male respondents $(N=133)$ compared with only 14 percent of women $(N=124)$ stated that they played digital games with others in-person 'every time' or 'most of the time' $\left(x^{2}=29.494, p<.001\right)$.

4.27 However, this does not necessarily mean that mobile telephone gaming is a wholly individualistic act. Though undoubtedly the vast majority of mobile and other 'mini' games are single player, interviewees who played these frequently mentioned that these were still sometimes (and for some, quite frequently) sources of conversation. For instance, two interviewees indicated that they would frequently discuss and exchange mobile telephone based games with their friends; such as 'Vicky' (female, aged 23) stated:

I got Bluetooth [which allows wireless data transfer] on my 'phone, so like me mates, 'cos loads of 'em have got the same one [telephone], so we talk about what games we got and swap 'em all the time. It's great fun...I got this new one today from my friend...we chat about 'em at uni' and we'll text each other at night, to say stuff like 'what you playing?', 'and how you doing [on it]?', which is always good if we're playing the same game at the same time.

4.28 However, the assertion that women are more likely to play 'mini' and mobile games due to restrictions placed upon their leisure time due to continued domestic responsibilities (Krotoski 2004) is probably less applicable to this sample group, as the vast majority of questionnaire respondents and interviewees were university students living away from their family homes and with other students. Most notable here, is that certain games technologies (such as PC/Macs and games consoles) and particular types of games (such as sport related games) continue to be aimed at male markets, and are symbolically and culturally seen as not the property of women. In contrast, mobile telephone technologies allow women easy and quick access to digital gaming in ways that tend to be less gender specific. However, the use of mobile gaming technologies by women and the meaning these hold for them is an area that requires a significant amount of further research and consideration.

4.29 Women in this research also appeared less likely to play digital games online. For instance, 88 percent of the female respondents $(N=124)$ suggested that they would 'never' play digital games with others online compared with 76 percent of men $(N=133)$. Though the distinction between the popularity of playing digital games online for both men and women was not statistically significant $(p>.05)$, this data supports the assertion made by authors such as Taylor (2003) that female players continue to be a minority in many online games ${ }^{[1]}$. However, again these findings may be particular to this data set, and even though women continue to constitute a minority in most online games (Taylor 2003), oncemore this should not preclude academic consideration of female gamers who do participate in these. Particularly since Bryce and Rutter (2003a: 11) suggest there is growing evidence to indicate that the number of women playing online games is increasing. Taylor (2003) suggests that massively multi-player online role-playing games (MMPORPG) such as Everquest and Ultima Online provide women with freedom and opportunities frequently denied to them away from the gaming screen. For instance, MMPORPGs allow women the freedom to explore online worlds and 'public' spaces and compete with men on a (more) equal footing, which is often denied to most women 'in real life' (or 'irl', as many online gamers refer to it) (Taylor 2003).

4.30 Though, only one female interviewee ('Mary', aged 21) indicated that she had frequently (but no longer) played games online, she did emphasise the freedom this allowed her, as one of its most appealing qualities:

I don't play games online much now, but I did when I was back home, I quite liked it...sometimes, I would play his [her brother's] character, and be a man, as it was often less hassle. But I really liked being this one female character I got, which is really tough, because you can just take no shit off men... they think you're weak because you're a woman, but you can just kick their heads in if they mess with you... it can be really funny...I like the sense of power that gives you [laughs]. I know it's not real, but it feels a bit like beating men at their own game....and that's cool.

4.31 The importance of online gaming (particularly for women) is an area that requires further research and discussion, as it does appear to offer an interesting and significant location (both physically and culturally) to consider gender relations within gaming.

\section{Conclusion}

5.1 This research indicates that women within this sample appeared a lot less likely to play digital games, and those who did, played these a lot less frequently than their male peers. This supports the assertion of Krotoski (2004) that women constitute less than a third of 'active gamers' in the UK. However, this does not necessarily contradict the findings of research conducted on school children (such as Funk 1993, Kafai 1996, Roe and Muijus 1998, Littleton et al. 1998, Colwell and Payne 2000), which suggest that more young 
girls are now playing digital games.

5.2 Though research (such as Kerr 2003) suggests that many men actively encourage women to play digital games, games continue to be designed and targeted primarily towards men, and access to gaming continues to be frequently controlled and regulated by male family members. Hence, the continued social and cultural control of gaming by men means that many women still do not see gaming as 'theirs'. Hence, this research suggests that when women leave the family home, such as to go away to university, they appear significantly less likely than their male counterparts to continue playing these games.

5.3 However, it is evident that some women do play digital games, and for some this can be both an important and sociable leisure activity. We do not wish to suggest that the needs or interests of women (or men) are homogenous, nor that all women would wish to play digital games. It was evident that women within this research had often quite diverse interests. For instance, some women enjoyed playing genres of games that would have primarily been designed and marketed towards men, such as sport related games, while some gamers preferred more 'feminine' or gender neutral games, such a dance mat games, while others had no interest in gaming at all. But there still appears to be a notable divide in the experiences of many male and female gamers. In particular, what proved quite notable in this research is the propensity for many women to play games on mobile telephones. The reason offered for this, is that mobile telephones tend to be less gendered than many other information and communication technologies; hence, these are often more readily accessible to women and less controlled by men. However, this does not mean that these were necessarily less sociable, and for some, could prove a popular source of conversation and interaction between friends. However, this is an area (as with the general relationship women have with gaming) that requires further and more detailed research and consideration, and it is hoped that this paper will stimulate further interest and debate in this field.

\section{Notes}

${ }^{1}$ For instance, Taylor (2003) suggests that women make up around 20-30 percent of players on massively multiplayer online games such as Asheron's Call, Ultima Online and Everquest. However, there are notable exceptions, such as the Korean based online game Lineage, which frequently boasts a higher proportion of female to male games (Krotoski 2004), or Ragnarok Online which at one pointed had over 80 percent female gamers, until Krotoski (2004) suggests (relying on anecdotal evidence) this gender balance became more equal once many male gamers became aware of this.

\section{References}

BUCHANAN, D.D. and Funk, J.B., (1996) 'Video and Computer Games in the 90s: Children's Time Commitment and Games Preferences', Children Today, 24, 12-15.

BRYCE, J. and Rutter, J. (2001) 'In the Game -In the Flow: Presence in Public Computer Gaming', poster presented at Computer Games and Digital Textualities , IT University of Copenhagen, March $<$ http://www.digiplay.org.uk>.

BRYCE, J. and Rutter, J. (2002) 'Killing Like a Girl: Gendered Gaming and Girl Gamer's Visibility', paper presented at Computer Games and Digital Cultures , Tampere, Finland, June 2002.

BRYCE, J. and Rutter, J (2003a) 'The Gendering of Computer Gaming: Experiences and Space', in S. Fleming and I. Jones (eds) Leisure Cultures: Investigations in Sport, Media and Technology, Leisure Studies Association, 3-22.

BRYCE, J. and Rutter, J (2003b) 'Gender Dynamics and the Social and Spatial Organization of Computer Gaming', Leisure Studies, 22, 1-15.

CASE, S. (2004) 'Women in Gaming, Windows XP Home, < http://www.microsoft.com/windowsxp/games/learnmore/womeningames.mspx>.

CASSELL, J. and Jenkins, H. (2000) 'Chess for Girls: Feminisms and Computer Games', in J. Cassell and H. Jenkins (eds) From Barbie to Mortal Combat: Gender and Computer Games , MIT Press, London, 2-45.

COLWELL, J., Grady, C. and Rhaiti, S. (1995) 'Computer Games, Self-Esteem and Gratification of Needs in Adolescents', Journal of Communication and Applied Social Psychology , 5 (3), 195-206. 
CRAWFORD, G. (2005) 'Digital Gaming, Sport and Gender', Leisure Studies, (forthcoming).

CRAWFORD, G. and Gosling, V.K. (2004) 'The Myth of the Puck Bunny: Female Fans and Men's Ice Hockey', Sociology, 38 (3), 477-493.

DEEM, R. (1982) 'Women, Leisure and Inequality', Leisure Studies 1(1), 29-46.

DEEM, R (1986) All Work and No Play?, Open University Press, Milton Keynes.

DIETZ, T.L. (1998) 'An Examination of Violence and Gender Role Portrayals in Video Games: Implications for Gender Socialization and Aggressive Behaviour', Sex Roles, 38 (5-6), 426-442.

DIGIPLAY (no date) Digiplay Interactive <http://www.digiplay.org.uk >.

ELSPA (2003) The Cultural Life of Computer and Video Games: A Cross Industry Study , Entertainment and Leisure Software Publishers Association.

ESA (2004) Entertainment Software Association <http://www.theesa.com/>.

FISKE, J. (1989a) Understanding Popular Culture, Unwin Hyman, London.

FISKE, J (1989b) Reading the Popular, Unwin Hyman, London.

FUNK, J.B. (1993) 'Reevaluating the Impact of Computer Games', Clinical Pediatrics, 32, 86-90.

FRISSEN, V. (1995) 'Gender is calling: some reflections on past, present and future uses of the telephone' in K. Grint and R. Gills (eds) The Gender-technology Relation: Contemporary Theory and Research, Taylor and Francis, London.

GREEN, E. (2001) 'Technology, Leisure and Everyday Practices' in E. Green and A. Adams (eds) Virtual Gender: Technology, Consumption and Identity, Routledge, London.

GREENFIELD, P.M. (1996) 'Video Games as Cultural Artifacts', Special Issue: Effects of Interactive Environment Technologies on Development, Journal of Applied Developmental Psychology , 15, 3-12.

HADDON, L. (1992) 'Explaining ICT Consumption: The Case of the Home Computer' in R. Silverstone and E. Hirsch (eds) Consuming Technologies: Media and Information in Domestic Spaces, Routledge, London, 82-96.

JENKINS, H. (1992) Textual Poachers, Routledge, London.

JENKINS, H (2000) "Complete Freedom of Movement': Video Games as Gendered Play Spaces', in J. Cassell and H. Jenkins (eds) From Barbie to Mortal Combat: Gender and Computer Games , MIT Press, London.

KAFAI, Y.B. (1996) 'Electronic Play Worlds: Gender Differences in Children's Construction of Video Games', in Y.B. Kafai and M.Resnick (eds) Constructionism in Practice: Designing, Thinking and Learning in a Digital World, Ablex, Mahwah NJ, 97-111.

KERR, A. (2003) 'Girls Just Want to Have Fun!', SIGIS, <http://www.rcss.ed.ac.uk/sigis/public/documents/SIGIS_D05_2.08_DCU3.pdf>.

KINDER, M. (1991) Playing with Power in Movies, Television and Video Games: From Muppet Babies to Teenage Mutant Ninja Turtles, University of Berkley Press, Berkley.

KROTOSKI, A. (2004) Chicks and Joysticks: An Exploration of Women and Gaming , ELSPA White Paper $<$ http://www.elspa.com/about/pr/elspawhitepaper3.pdf >.

LITTLETON, K., Light, P., Joiner, R., Messer, D. and Barnes, P. (1998) 'Gender, Task Scenarios and Children's Computer-based Problem Solving', Educational Psychology, 18 (3), 327-340.

MCNAMEE, S. (1998) 'Youth, Gender and Video Games: Power and Control in the Home' in T. Skelton and G. Valentine (eds) Cool Places: Geographies of Youth Cultures, Routledge, London.

PILCHER, J. (1999) Women in Contemporary Britain: An Introduction, Routledge, London.

ROE, K. and Muijus, D. (1998) 'Children and Computer Games', European Journal of Communication , 13 (2), 181-200. 
SHAW, S.M. (1994) Gender, Leisure and Constraint: Towards a Framework for Analysis of Women's Leisure, Journal of Leisure Research , 26, 8-22.

SILVERSTONE, R., Hirsch, E. and Morley, D. (1992) 'Economy of the Household' in R. Silverstone and E. Hirsch (eds) Consuming Technologies: Media and Information in Domestic Spaces, Routledge, London.

TAYLOR, T.L. (2003) 'Multiple Pleasures: Women and Online Gaming', Convergence, 9 (1), 21-46.

WEARING, B. (1998) Leisure and Feminist Theory, Sage, London.

YATES, S. J. and Littleton, K. L. (2001) 'Understanding Computer Game Culture: A Situated Approach' in E. Green and A. Adams (eds) Virtual Gender: Technology, Consumption and Identity, Routledge, London, 103123. 